\title{
Choosing Physics as a Specialization in Graduate Studies: Views and Factors Affecting It
}

\author{
Mae Anne R. Migue \\ Visayas State University- Tolosa Campus, Philippines
}

\begin{abstract}
Physics is one of the complex science subject and students taking tertiary science education courses do not choose physics as their specialization. The Philippine Normal University was also experiencing the same, only few graduate students choose the said subject as a specialization. With this, the researcher seeks to find out the views and factors affecting the situation. The data shows that the p-value calculated for the negative views towards Physics as well as factors affecting it is less than $(<)$ the $\alpha$ which is 0.05 . Thus, the negative views towards Physics and the factors affecting it has significant relationship with the decision of choosing Physics as a major.
\end{abstract}

Keywords: Physics Education, Physics Specialization

\section{INTRODUCTION}

$\mathrm{S}^{\mathrm{c}}$ cience education is a tool for developing country's strength in science and technology. Science has been a part of our daily lives and it involves a lot of branches including Biology, Chemistry, Earth sciences, Astronomy and Physics. Among the mentioned branches of science, Physics has shown to be the driver of innovation and advancement, this in turn has made life more convenient than ever. From the gadgets and appliances, we used at home, in school and everything around us. From the means of transportation as well as electricity and many more, all are product of Physics. And according to Saleh (2014) Physics is basically a study to find the answers to the questions of 'why' and 'how' natural phenomena in daily life occur.

Physics is thought in classrooms and despite its importance to our daily activities, it is considered as an unessential and boring subject due to the abstractness of the topics discussed as well as the difficulty in understandingand misconceptions about the laws and theories underpinning the subject (Kizilcik \&Yavas, 2017). This problem has been an obstacle to development over the years in Physics, which has in turn denied the field several achievements across the world. And according to Orleans (2007), the Philippines lag behind other countries in terms of students' achievement in science. And not only the Philippines but other countries supported by other researches. There is also issues on the choice of taking Physics as a specialization and there are only few teachers who wish to specialize Physics. Nowadays, there are only few students who possesses that enthusiasm towards Physics and this is an international problem (Saleh, 2010). Thus, this study wishes to know the views of these teachers who tend not to choose Physics as their specialization though they have the chance of majoring it. The study also aims to know the factors affecting their views towards Physics and if it affects their decision in specializing it.

\section{LITERATURE REVIEW}

Science is a broad and wide subject matter. It encompasses different fields, the life sciences and physical sciences. Life sciences simply deals with Biology and its branches. On the other hand, physical sciences deal with Astronomy, Chemistry, Physics and their branches. It is also very essential to every country to promote quality science education for the people and also for the economy. But for many years, it has been evident that the interest towards science and technology is decreasing (Ekici, 2016).

As a developing country, science education has been a part of our curriculum for so many years. As mentioned, Physics is one of the field of sciences. It is the study of life phenomena and are expounded by the fundamental laws of nature (Padua, Ramos \& Rabago, 2010 and Aksakalli, Salar, \& Turgut, 2016). Cutnell and Johnson (2013) said that it was developed out of the efforts of men and women to explain the physical environment. It also a dynamic discipline of science, it always develops abruptly through the years because of new inventions, innovations and space explorations.

According to Saleh (2014) Physics is basically a study to find the answers to the questions of 'why' and 'how' natural phenomena in daily life occur. Its theories, principles and concepts are applied in day to day activities such as in the use of technology--- electricity, gadgets and transportation (Hamelo, 2016; Bezen, Bayrak, Aykutlu, 2016 and Demir, Sincar \& Celik, 2015). It deals with different concepts on Thermodynamics, Quantum Mechanics, Classical Physics, Electricity and Magnetism, Kinematics, Optics and Modern Physics (Buabeng, Conner \& Winter, 2016; Cutnell \& Jonson, 2013 and Padua, Ramos \& Rabago, 2010).

As mentioned by Samelo (2010), one of the international problems nowadays is that there are only few students who possesses that enthusiasm towards Physics. Many undergraduate students who are enrolled in education program do not choose Physics as their field of specialization because they find it hard due to low Physics identity which pertains to interest, performance, competence, and recognition (Saleh, 2014 and Stiles-Clarke \& MacLeod, 2016). And thus, producing few teachers majoring in Physics who currently are teaching in the field. 


\section{Students' Attitude towards Physics}

In the study of Korur and Eryilmaz (2012), they sighted the work of Korur 2001 and 2008 that states that physics teacher characteristics affects student achievement, motivation, and attitude. Physics is said to a boring subject among students in secondary schools especially in the rural areas (Veloo, Nor \& Khalid, 2015). In the study of Orleans (2007), it is shown that the Philippines lags behind in Physics education than that of other countries. Teachers have always remarked by their students' performance in Physics achievement due to their negative attitude and lack of interest towards the subject and in order for teachers to be able to teach Physics effectively, there is a need in improving students' positive attitude towards the subject (Veloo, Nor \& Khalid, 2015).

In the study of Sahin, Caliskan \& Dilek (2015), they mentioned that science anxiety could be one reason for students poor performance in Physics. Science anxiety, as stated in the study, can also be related to family, school, or environment where they experience fear and negative emotion. With this, we can say that the students' views and the factors affecting their views towards Physics might affect their future plans of choosing any branch of science, especially Physics as a specialization. As cited by Saleh (2014), there are researches confirming that the motivation level of students towards Physics is significantly low and is affected by pressure, effort, stress and value. Motivation is very important because it increases students' interest and passion towards learning.

\section{Physics as an Abstract Subject}

Physics is hard to understand for the students due to misunderstanding and misconception (Kizilcik \&Yavas, 2017). It is a subject that is considered difficult to learn as well as to teach (Ekici, 2016). The fact that Physics does not only deal with theories and concepts, the student should also have the skills of analyzing word problems, deriving formulas and understanding graphs and figures (Saleh, 2014). These ads up to the reason why Physics is considered a cost for other students who lack the skills. The fact that Physics involves mathematical treatment of data which involves algebraic equations and mathematical symbols.

It is also evident that the importance between their relationships to each other is increasing but most Physics teachers are complaining because nowadays students lack mathematical skills (Al-Omari \& Miqdadi, 2014). Because of these many students that fear Physics because of the hindering factor that mathematics is a tool to learn the subject. According to Ataide \& Greca, (2013), as cited by Kapucu, Oçal, \&Simşek (2016), students need to have a deep understanding of mathematics and utilize it when necessary while engaging with physics concepts.

\section{Physics Experience}

Many students view Physics as a hard subject because it is abstract and involves mathematical treatment in order for a certain concept to be fully understood. But their views towards the subject may be affected also with the type of teacher they have (Samelo, 2010). One factor that affects students' learning is the experience they had in the classroom which includes teacher actions and behaviors from the beginning till the end of a lesson (Korur \&Eryılmaz, 2012). Physics involves topics that are a part of the daily activities of the students. Thus, teaching Physics would be easier if teachers could relate students' experiences to Physics topics which is seldom done in the classroom.

\section{THEORETICAL FRAMEWORK}

The study conducted is based on Brofenbrenner's Ecological Systems Theory (1979) that shows that the process of personal development is influenced by its interaction with its environment. Certain decisions that an individual may adhere to could be shaped by their experiences during their interaction with their family, peers, teachers, school, church and their community. The Ecological Systems Theory are divided into four systems that an individual was able to interact with during childhood up to present that may affect their views towards something.

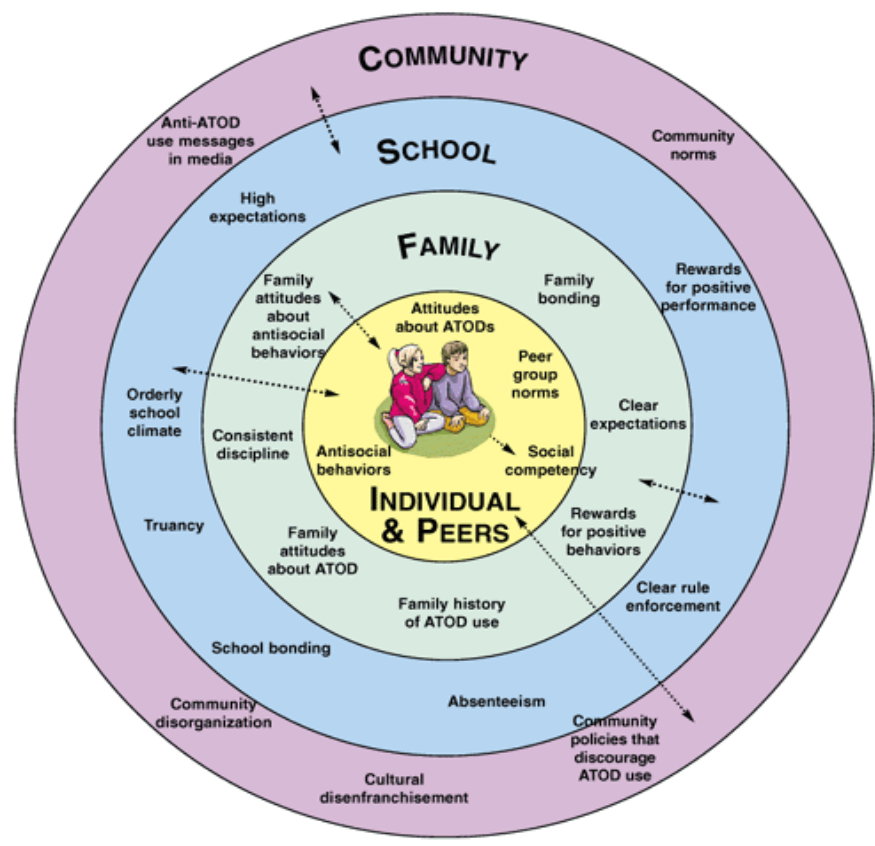

Figure no 1. Brofenbrenner's Ecological Systems Theory

Microsystem refers to the system that directly shaped the child's development that includes their family, school, religion, and peers.

Mesosystem refers to the interactions of the microsystem like family and teacher relationship when an individual is in school and also religion and family as well as its peers.

Exosystem are links or involvement between a social setting in which the individual does not have an active participation or role. For example, a child's experience may be affected with the experience of their family's problem at work. Or their 
decision may be affected with the current issues in the government and many more.

Macrosystem describes the culture the child is interacting. The way an individual behave may be affected by the culture and traditions they are in.

\section{Conceptual Framework}

This study is anchored with conceptual framework shown below that seeks to know the negative views of non-physics graduate students towards choosing Physics as a major and the factors affecting their views.

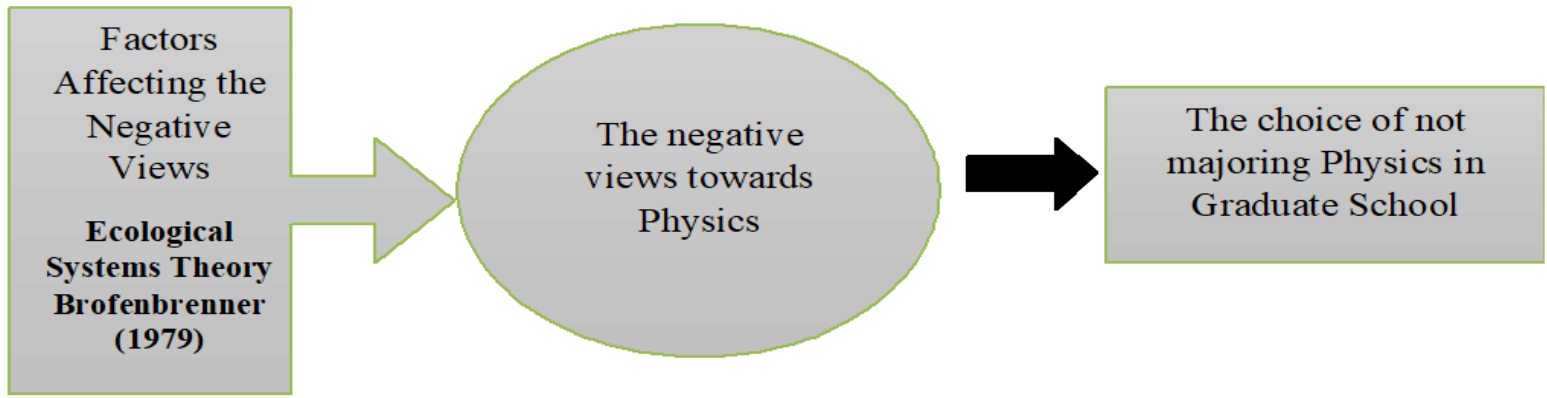

Figure no 2. Conceptual Framework

This shows that the choice of not majoring Physics in graduate school is influenced by their negative views towards Physics as a subject. These negative views are directly shaped by different factors that are based on their experiences that has been a part of their personal development and decision making. These factors may be influenced in different levels that can be identify using Brofenbrenner's Ecological Systems Theory (1979).

\section{RESEARCH PROBLEMS AND HYPOTHESIS}

\section{Statement of the Problem}

One major issue nowadays is the declining number of students who wishes to choose Physics as their major of specialization (Samelo, 2010 and Stiles-Clarke \& MacLeod, 2016). Thus, this study is aimed to know the factors that affect the negative views of Philippine Normal University's Master of Arts in Science Education students, whose undergraduate degree was General Science, Physical Sciences and Physics towards choosing Physics as a specialization by answering the following questions.

- What are the negative views towards Physics and the factors affecting it?

- Is there a significant relationship between choosing Physics as a specialization or not in the graduate school to the factors that affects their negative views towards Physics?

- Is there a significant relationship between choosing Physics as a specialization or not in the graduate school to the negative views towards Physics?

\section{Null Hypothesis}

Students who majored general science, physical science and physics during their undergraduate program has all the choice to major different specialization in graduate school. The choice of whether to major Physics or not may depend on their views towards Physics and the actors affecting it or not at all. Thus, the researcher come up with the following hypothesis.

1. There is no significant relationship between choosing Physics as a specialization or not in the graduate school to the negative views towards Physics.

2. There is no significant relationship between choosing Physics as a specialization or not in the graduate school to the factors that affects their views towards Physics.

\section{METHODOLOGY}

\section{Research Design}

In this quantitative study that seeks to know the negative views of science teachers towards majoring Physics in the graduate school and the factors affecting it a descriptive survey method was used. A descriptive survey method is the collecting of data of quantitative and numeric descriptions of views, opinions and trends of a sample population (Creswell, 2014). This method will allow the researcher to know the negative views they have towards Physics and if it affects their choice of majorship. The study also tries to find out the different factors affecting their views towards the subject.

\section{Sampling and Participants}

The sampling technique used by the researcher is purposive sampling. It is a sampling technique used for selecting participants for some specific reason. The participants of this study are 15 graduate students from Philippine Normal University whose specialization could either be Chemistry, Biology and Integrated Science and should also have an undergraduate degree in education whose major could either be General Science, Physical Science and Physics. This would allow the researcher to gather enough information by further eliciting their views towards majoring physics and the factors affecting. And that, the sampling technique used will be able 
to identify the participant that will fit to the criteria of the study that has been conducted.

\section{Research Instrument}

The research instrument used in the study conducted is a descriptive survey consisting of Likert scales. The scales in the research instrument are 5- strongly agree, 4- agree, 3neutral, 2-disagree, and 1- strongly disagree. The instrument was designed by the researcher and was anchored with different findings of the related study that was reviewed as well as Brofenbrenner's Ecological Theory. It is consisting of two parts. The first part is the views of the participants towards Physics and the second part is focusing on the factors affecting their views.

\section{Data Gathering Procedure}

The data was gathered by selecting first the respondents of the study through purposive sampling. This is to assure that the respondents will fit to the criteria of the study and that be able to gather quality information for the study. Second, a letter was distributed to the participants together with the questionnaire. The letter is asking for the approval of the respondents to willingly participate in the study and an assurance that the data gathered from the participants will be treated with utmost confidentiality.

\section{Data Analysis}

The data was analysed through finding the frequency and percentage of each item. Since the research instrument is a Likert Scale questionnaire a non-parametric test was also used by the researcher to identify the p- value of the overall data for the researcher to be able to identify whether to reject or accept the null hypothesis. The test used is the Chi-Square Test and $\alpha$-value used in this study is 0.05 with the help of SPSS Tool.

\section{Ethical Considerations}

Ethical issues and considerations in conducting a study is very crucial. Ethics are the norms and standards that we follow to establish respect towards the participants. Since the study focuses on the views of teachers who didn't specialize Physics towards choosing it as a field of specialization and the factors affecting their views, this study assures that the data gathered from the participants will be treated with utmost confidentiality. A letter of intent was also given to the respondents to let them know the scope of the study and that the data will be used for the purpose of answering the research questions under the limitations of the study.

\section{RESULTS AND DISCUSSION}

This chapter presents the data analysis and findings of the researcher about the study conducted. The study findings are presented on the negative views towards Physics and the factors affecting it as well as if it influences the choice of majoring not majoring Physics in graduate school. The data was gathered exclusively from the questionnaire as the research instruments. The questionnaires were designed in line with the objectives of the study.

\section{Participants}

The participants of the study are 15 graduate students who's not taking Physics as a specialization in graduate school. But their undergraduate major could either be General Science, Physical Sciences and Physics.

Table no 1. Participants of the Study

\begin{tabular}{|c|c|c|}
\hline Specialization & No. & Percentage \\
\hline Integrated Science & 5 & $33.3 \%$ \\
\hline Biology & 5 & $33.3 \%$ \\
\hline Chemistry & 5 & $33.3 \%$ \\
\hline Total & 15 & $100 \%$ \\
\hline
\end{tabular}

Table no. 1 shows the specialization taken by the respondents in their graduate degree. $33.3 \%$ of the participants are specializing Integrated Science, $33.3 \%$ are specializing Biology and $33.3 \%$ are specializing Chemistry.

\section{Negative Views towards Physics and the Factors Affecting It}

The first objective of this study is to know the different negative views of the participants towards Physics and the factors affecting it. In the study conducted different negative views towards Physics were presented to them as well as factors affecting their views. They were to identify whether they strongly agree, agree, feel neutral, disagree or strongly agree on each statement. The data collected from the participants are shown.

Table no 2: Frequency of Responses for the Negative Views towards Physics

\begin{tabular}{|c|c|c|c|c|c|c|c|c|c|c|c|c|}
\hline \multirow{2}{*}{ Physics.., } & \multicolumn{2}{|c|}{ SA } & \multicolumn{2}{|c|}{ A } & \multicolumn{2}{|c|}{$\mathrm{N}$} & \multicolumn{2}{|c|}{$\mathrm{D}$} & \multicolumn{2}{|c|}{ SD } & \multicolumn{2}{|c|}{ Total } \\
\hline & $f$ & $\%$ & $f$ & $\%$ & $f$ & $\%$ & $F$ & $\%$ & $f$ & $\%$ & $f$ & $\%$ \\
\hline 1. Is a boring subject. & 3 & 20.0 & 10 & 66.7 & 1 & 6.7 & 0 & 0.0 & 1 & 6.7 & 15 & 100 \\
\hline $\begin{array}{l}\text { 2. Involves abstract concepts and } \\
\text { theories that is difficult. }\end{array}$ & 5 & 33.3 & 9 & 60.0 & 0 & 0.0 & 0 & 0.0 & 1 & 6.7 & 15 & 100 \\
\hline 3. Is not an interesting subject. & 3 & 20.0 & 10 & 66.7 & 0 & 0.0 & 1 & 6.7 & 1 & 6.7 & 15 & 100 \\
\hline $\begin{array}{l}\text { 4. Can be learn thoroughly if you are } \\
\text { mathematically skilled. }\end{array}$ & 5 & 33.3 & 9 & 60.0 & 0 & 0.0 & 1 & 6.7 & 0 & 0.0 & 15 & 100 \\
\hline 5. Is not a motivating subject. & 5 & 33.3 & 8 & 53.3 & 0 & 0.0 & 1 & 6.7 & 1 & 6.7 & 15 & 100 \\
\hline $\begin{array}{l}\text { 6. Is not applicable in the field of } \\
\text { work. }\end{array}$ & 5 & 33.3 & 9 & 60.0 & 0 & 0.0 & 0 & 0.0 & 1 & 6.7 & 15 & 100 \\
\hline
\end{tabular}




\begin{tabular}{|c|c|c|c|c|c|c|c|c|c|c|c|c|}
\hline 7. Is hard to teach to students. & 3 & 20.0 & 11 & 73.3 & 0 & 0.0 & 1 & 6.7 & 0 & 0.0 & 15 & 100 \\
\hline $\begin{array}{l}\text { 8. Involves few laboratory and } \\
\text { exploratory activities, mostly involve } \\
\text { solving. }\end{array}$ & 5 & 33.3 & 9 & 60.0 & 0 & 0.0 & 0 & 0.0 & 1 & 6.7 & 15 & 100 \\
\hline $\begin{array}{l}\text { 9. Is mostly learned through reading } \\
\text { thick Physics books. }\end{array}$ & 3 & 20.0 & 11 & 73.3 & 0 & 0.0 & 0 & 0.0 & 1 & 6.7 & 15 & 100 \\
\hline 10. Is hard to understand. & 4 & 26.7 & 10 & 66.7 & 0 & 0.0 & 0 & 0.0 & 1 & 6.7 & 15 & 100 \\
\hline
\end{tabular}

Table no. 2: shows the negative views towards Physics a bar graph was also presented to show the responses of the participants in each item in the first part of the questionnaire.

Graph no 1. Negative Views towards Physics

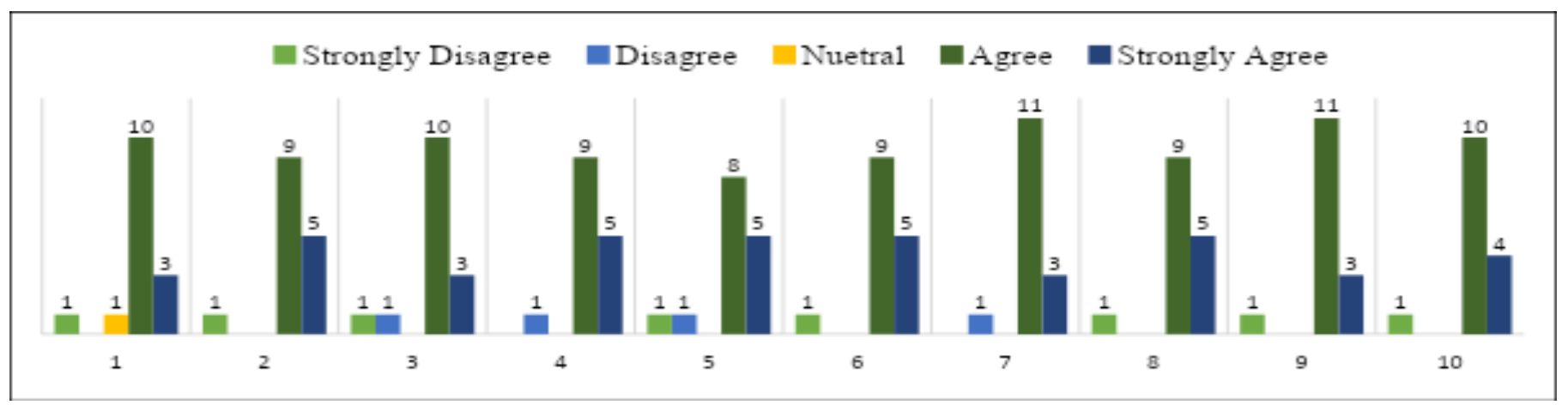

Table no. 2 and Graph no. 1 shows that $86.7 \%$ agreed to consider and agreed Physics as a boring subject and it is not an interesting and motivating subject. Also, 93.3\% agreed that the subject involves abstract concepts that are difficult, it can also be learned thoroughly if you are mathematically skilled, it is not applicable in the field of work and it is hard to t each to students, involves few laboratory activities, mostly learned through reading and is hard to understand. Only $6.7 \%$ of the participants disagree that Physics is a boring subject and it involves abstract concepts that are difficult, that it can be learned only if you are mathematically skilled, hard to teach, involves few laboratory activities and mostly involves solving, is mostly learned through reading and is hard to understand. Also, $13.4 \%$ disagreed that Physics is not an interesting and motivating subject.

Table no 3: Frequency of Responses for the Factors Affecting the Negative Views towards Physics

\begin{tabular}{|c|c|c|c|c|c|c|c|c|c|c|c|c|}
\hline & \multicolumn{2}{|c|}{ SA } & \multicolumn{2}{|c|}{ A } & \multicolumn{2}{|c|}{$\mathrm{N}$} & \multicolumn{2}{|c|}{$\mathrm{D}$} & \multicolumn{2}{|c|}{ SD } & \multicolumn{2}{|c|}{ Total } \\
\hline & $f$ & $\%$ & $f$ & $\%$ & $f$ & $\%$ & $f$ & $\%$ & $F$ & $\%$ & $f$ & $\%$ \\
\hline $\begin{array}{l}\text { 1. My teachers in Physics were not able to } \\
\text { discuss the topics effectively in our Physics } \\
\text { class. }\end{array}$ & 7 & 46.7 & 6 & 40.0 & 1 & 6.7 & 0 & 0.0 & 1 & 6.7 & 15 & 100 \\
\hline 2. I have low level skills in mathematics. & 4 & 26.7 & 10 & 66.7 & 0 & 0.0 & 0 & 0.0 & 1 & 6.7 & 15 & 100 \\
\hline $\begin{array}{l}\text { 3. I have difficulties in interpreting } \\
\text { mathematical symbols and equations. }\end{array}$ & 5 & 33.3 & 9 & 60.0 & 0 & 0.0 & 0 & 0.0 & 1 & 6.7 & 15 & 100 \\
\hline $\begin{array}{l}\text { 4. I don't feel the enthusiasm and eagerness } \\
\text { during Physics subject. }\end{array}$ & 4 & 26.7 & 10 & 66.7 & 0 & 0.0 & 0 & 0.0 & 1 & 6.7 & 15 & 100 \\
\hline 5. Physics is a memorization-based course. & 4 & 26.7 & 10 & 66.7 & 1 & 6.7 & 0 & 0.0 & 0 & 0.0 & 15 & 100 \\
\hline $\begin{array}{l}\text { 6. My teacher in Physics fails to establish } \\
\text { analogies. }\end{array}$ & 1 & 6.7 & 13 & 86.7 & 0 & 0.0 & 0 & 0.0 & 1 & 6.7 & 15 & 100 \\
\hline $\begin{array}{l}\text { 7. My physics experience during my } \\
\text { undergraduate degree is not considered as a } \\
\text { fun learning. }\end{array}$ & 4 & 26.7 & 10 & 66.7 & 0 & 0.0 & 1 & 6.7 & 0 & 0.0 & 15 & 100 \\
\hline $\begin{array}{l}\text { 8. I learned the subject mostly through } \\
\text { discussion and few on laboratory activities. }\end{array}$ & 2 & 13.3 & 12 & 80.0 & 0 & 0.0 & 0 & 0.0 & 1 & 6.7 & 15 & 100 \\
\hline $\begin{array}{l}\text { 9. Physics concepts involves complex } \\
\text { formulas that is hard to understand. }\end{array}$ & 5 & 33.3 & 9 & 60.0 & 0 & 0.0 & 1 & 6.7 & 0 & 0.0 & 15 & 100 \\
\hline $\begin{array}{l}\text { 10. There is a lack of clear translation of } \\
\text { Physics textbooks. }\end{array}$ & 3 & 20.0 & 11 & 73.3 & 0 & 0.0 & 0 & 0.0 & 1 & 6.7 & 15 & 100 \\
\hline
\end{tabular}


With the tabulated responses on Table no. 2 about the factors affecting the negative views towards Physics a bar graph was also presented to show the responses of the participants in each item in the second part of the questionnaire.

Graph no 2. Factors Affecting Negative Views towards Physics

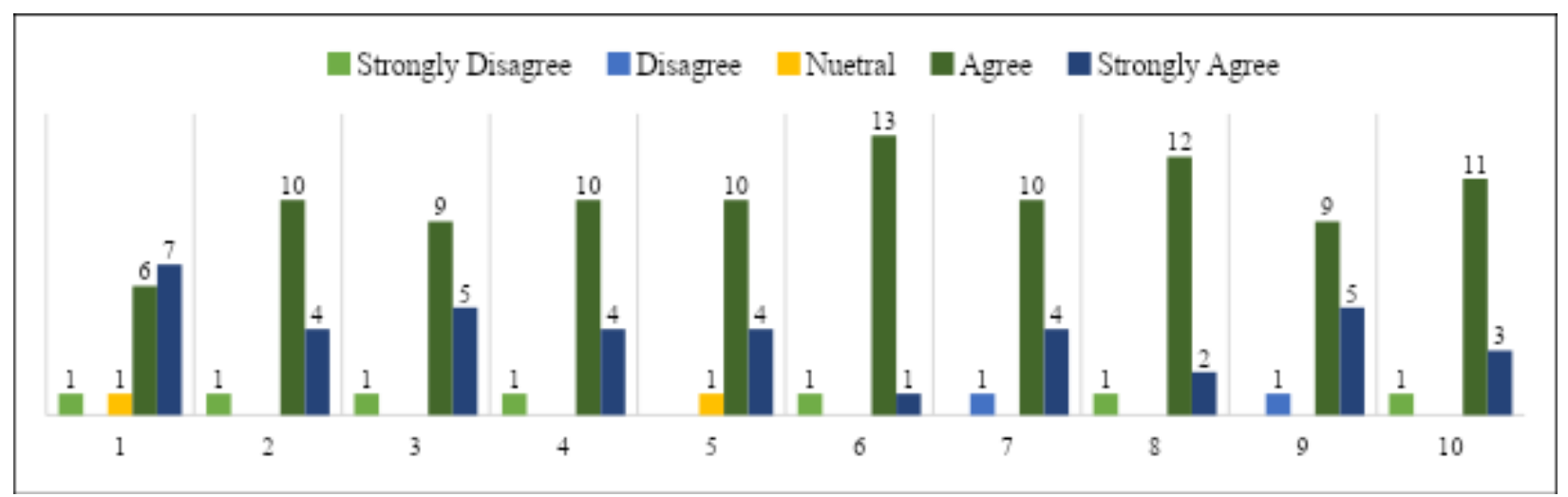

Table no.3 and Graph no. 2 shows that $93.3 \%$ of the participants agreed that they have low skills in mathematics and have difficulty in interpreting mathematical symbols and equations, that they don't have enthusiasm towards Physics , that Physics is a memorization-based course, that their teachers in Physics fails to establish analogies, that they don't consider their Physics experience as a fun learning, that they learned the subject mostly through discussions and few on laboratory activities, that the subject consists of formulas that is hard to understand and the concepts has no clear translation on textbooks. And also, $86.7 \%$ agreed that their Physics teachers were not able to discuss topics effectively in their Physics class. Only $6.7 \%$ of the participants disagreed that agreed that they have low skills in mathematics and have difficulty in interpreting mathematical symbols and equations, that they don't have enthusiasm towards Physics, that Physics is a memorization-based course, that their teachers in Physics fails to establish analogies, that they don't consider their Physics experience as a fun learning, that they learned the subject mostly through discussions and few on laboratory activities, that the subject consists of formulas that is hard to understand, concepts has no clear translation on textbooks and their Physics teachers were not able to discuss topics effectively in their Physics class.

\section{Chi- Square Test Results}

The second and the third objective of the study is to know whether if there is a significant relationship between choosing Physics as a specialization or not in the graduate school to the factors that affects their negative views towards Physics and if there a significant relationship between choosing Physics as a specialization or not in the graduate school to the negative views towards Physics.

In this part the researcher presented the Chi-square test results of the responses of the participants. The actual response are the expected response were statistically treated to identify the significance of each item. The $\alpha$-value set by the researcher was set to 0.05 for this study.

Table no 4. Relationship between choosing Physics as a specialization and the Negative Views

\begin{tabular}{|c|c|c|c|c|c|c|c|c|c|c|}
\hline \multicolumn{11}{|c|}{ Negative Views Towards Physics } \\
\hline & 1 & 2 & 3 & 4 & 5 & 6 & 7 & 8 & 9 & 10 \\
\hline Chi-Square & $14.600^{\mathrm{a}}$ & $6.400^{\mathrm{b}}$ & $14.600^{\mathrm{a}}$ & $6.400^{\mathrm{b}}$ & $9.267^{\mathrm{a}}$ & $6.400^{\mathrm{b}}$ & $11.200^{\mathrm{b}}$ & $6.400^{\mathrm{b}}$ & $11.200^{\mathrm{b}}$ & $8.400^{\mathrm{b}}$ \\
\hline Df & 3 & 2 & 3 & 2 & 3 & 2 & 2 & 2 & 2 & 2 \\
\hline Asymp. Sig. & .002 & .041 & .002 & .041 & .026 & .041 & .004 & .041 & .004 & .015 \\
\hline
\end{tabular}

Table no. 4: shows that the p-value of each item is less than $(<) \alpha$ which is 0.05 . It shows that the negative views of the participants towards Physics has significant relationship to their choice of whether to specialized Physics or not in the graduate school. 
Table no 5: Relationship between choosing Physics as a specialization and the Factors Affecting the Negative Views towards Physics

\begin{tabular}{|c|c|c|c|c|c|c|c|c|c|c|}
\hline & 1 & 2 & 3 & 4 & 5 & 6 & 7 & 8 & 9 & 10 \\
\hline Chi-Square & $8.200^{\mathrm{a}}$ & $8.400^{\mathrm{b}}$ & $6.400^{\mathrm{b}}$ & $8.400^{\mathrm{b}}$ & $8.400^{\mathrm{b}}$ & $19.200^{\mathrm{b}}$ & $8.400^{\mathrm{b}}$ & $14.800^{\mathrm{b}}$ & $6.400^{\mathrm{b}}$ & $11.200^{\mathrm{b}}$ \\
\hline Df & 3 & 2 & 2 & 2 & 2 & 2 & 2 & 2 & 2 & 2 \\
\hline Asymp. Sig. & .042 & .015 & .041 & .015 & .015 & .000 & .015 & .001 & .041 & .004 \\
\hline
\end{tabular}

Table no. 5: shows that the p-value of each item is less than $(<) \alpha$ which is 0.05 . It shows that the factors affecting the negative views of the participants towards Physics has significant relationship to their choice of whether to specialized Physics or not in the graduate school.

\section{SUMMARY, CONCLUSIONS AND RECOMMENDATIONS}

\section{Summary}

In the study conducted by the researcher, the finding showed the negative views of the participants towards Physics. The participants consider Physics as a boring and not motivating subject. They also view Physics as a subject that can be learned thoroughly if you are mathematically skilled and it is not applicable in the field of work. It is hard to $t$ each to students, involves few laboratory activities, mostly learned through reading and is hard to understand. There are several factors affecting the negative views of the participants and mostly falls under Brofenbrenner's Ecological Theory at microsystem and mesosystem level or their experience in the school. They have low skills in mathematics and have difficulty in interpreting mathematical symbols and equations. They don't have enthusiasm towards Physics that could possibly influences by their experience during a Physics class. They consider Physics as a memorization-based course that their teachers in Physics fails to establish analogies, that they don't consider their Physics experience as a fun learning. They learned the subject mostly through discussions and few on laboratory activities, that the subject consists of formulas that is hard to understand, and the concepts has no clear translation on textbooks. And also, their Physics teachers were not able to discuss topics effectively in their Physics class. It also shows that the negative views towards Physics as well as the factors affecting it influences the choice of whether to major Physics or not.

\section{Limitations of the Study}

The study conducted was only limited to Philippine Normal University graduate students who are taking Master of Arts in Science Education and not majoring Physics. The participants should also have an undergraduate major of either General Sciences, Physical Sciences or Physics. There were only 15 participants because these are the only participants that qualifies to the needed requirement for a respondent be considered as a participant in the study.

\section{Conclusions}

With all the statistical analysis done with the data gathered from the participants, the data shows that the p-value calculated for the negative views towards Physics as well as factors affecting it is less than $(<)$ the $\alpha$ which is 0.05 . Thus, the study rejects the hypothesis and therefore conclude that the negative views towards Physics and the factors affecting it has significant relationship with the decision of choosing Physics as a major.

\section{Recommendations}

The study conducted shows that most of the negative views towards Physics is centered on the difficulty of the subject. It also shows that the main factor affecting the difficulty experience by the students are their academic experience in their teachers in Physics. In Brofenbrenner's Ecological Theory, in mesosystem or the interaction of the child to the school and with his teachers could influence their personal development as well as choices. Thus, I recommend the following;

a. To the future researchers: A study may be conducted to know the quality of Physics teachers in the Philippines and their teaching strategies. A research on developing a new pedagogy in teaching Physics may also be conducted that would address the needs as well as fear of the students towards Physics.

b. To the Department of Education: Seminars and trainings should be conducted for Physics teachers as well as annual assessment of their efficacy as a Physics teacher. There should also be a tracking for teachers that only Physics teachers should teach the subject to attain quality teaching and learning process.

c. To the Department of Science and Technology: They should increase the number of scholars that will take Physics for the country to have higher number of Physics majors that are equipped with skills in the field of teaching.

\section{REFERENCES}

[1] Aksakalli, A., Salar, R., \& Turgut, U. (2016). Investigation of the reasons of negative perceptions of undergraduate students 
regarding the modern physics course. European Journal of Science and Mathematics Education,

Vol. 4, No. 1, 2016, 44-55.

[2] Al-Omari, W., \& Miqdadi, R. (2014). The epistemological perceptions of the relationship between physics and mathematics and its effect on problem-solving among pre-service teachers at yarmouk university in jordan. International Education Studies, ISSN 1913-9020 Vol. 7, No. 5.

[3] Crisostomo, A.L., Ramos, H.J. and Rabago, L.M. (2010). Practical and explorational physics. Metro Manila. Vibal Publishing House Inc.

[4] Cutnell, J.D. and Johnson, K.W. (2013) Introduction to physics 9th edition. John Wiley \& Sons Singapore Pte. Ltd.

[5] Ekici, E. (2016). "Why do I slog through the physics?" understanding high school students' difficulties in learning physics. Journal of Education and Practice, ISSN 2222-1735 Vol.7, No.7.

[6] Hamelo, S. (2016). Interest of grade ten students toward physics among other science subjects, case of Wolaita Soddo town governmental secondary schools, Ethiopia. Journal of Education and Practice, ISSN 2222-1735 Vol.7, No.25.

[7] KAPUCU, S., ÖÇAL, M. F., \& ŞİMŞEK, M. (2016). Evaluating high school students' conceptions of the relationship between mathematics and physics: development of a questionnaire. Science Education International, Vol. 27, Issue2, 2016, 253-276.

[8] Kızılcık, H. Ş., \&Yavaş, P. Ü. (2017). Pre-service Physics Teachers' opinions about the difficulties in understanding introductory quantum physics topics. Journal of Education and Training Studies, E-ISSN 2324-8068 Vol. 5 No. 1.
[9] Korur, F., \&Ery1lmaz, A. (2012). Teachers' and students' perceptions of effective physics teacher characteristics. Eurasian Journal of Educational Research, Issue 46, Winter 2012,, 101120.

[10] Sahin, M., Caliskan , S., \&Dilek, U. (2015). Development and validation of the physics anxiety rating scale. International Journal of Environmental \& Science Education, 10(2), 183-200.

[11] Saleh, S. (2014). Malaysian students' motivation towards Physics learning

.European Journal of Science and Mathematics Education , Vol. 2, No. 4, 2014, 223-232.

[12] Semela, T. (2010). Who is joining physics and why? Factors influencing the choice of physics among Ethiopian university students. International Journal of Environmental \& Science Education, Vol. 05, No. 03.

[13] Stiles-Clark, L., \& MacLeod, K. (2016). Choosing to major in Physics, or not: factors affecting undergraduate decision making. European J of Physics Education, Volume 7 Issue 1 ISSN: 13097202 .

[14] Orleans, A. (2007). The condition of secondary school physics education in the Philippines: Recent development and remaining challenges for substantive improvements. Australian Educational Researcher Vol.34 No.4 April 2007

[15] Veloo, A., Nor, R., \& Khalid, R. (2015). Attitude towards physics and additional mathematics achievement towards physics achievement. International Education Studies; Vol. 8, No. 3, ISSN 1913-9020 E-ISSN 1913-9039 